\title{
Using accountability for mental health to drive reform
}

Sebastian P Rosenberg MPubAdmin

Ian B Hickie

MD

Patrick D McGorry PhD, MD, FRANZCP

Luis Salvador-Carulla MD, PhD

Jane Burns $\mathrm{BA}$ (Hons), PhD

Helen Christensen MPsych(Hons), PhD, FASSA

John Mendoza

BEd, GradDipHealthEd

Alan Rosen MBBS, FRANZCP

Lesley M Russell $\mathrm{BSc}$ (Hons), BA, PhD

Sally Sinclai BSc(Hons)

1 Brain and Mind Centre University of Sydne Sydney, NSW.

2 ORYGEN Youth Health Research Centre, University of Melbourne, Melbourne, VIC

3 Young and Well Cooperative Research Centre University of Melbourne Melbourne, VIC

4 Black Dog Institute Sydney, NSW.

5 ConNetica Consulting Caloundra, QLD.

6 School of Public Health, University of Wollongons Wollongong, NSW.

7 Australian Primary Health Care Research Institute Australian National

University, Canberra, ACT.

8 National Employment

Services Association

Melbourne, VIC.

sebastian.rosenberg@ sydney.edu.au

doi: 10.5694/mjal5.00447
A cross the health care system, accurate measurement and frequent transparent reporting of patient experiences has the capacity to reduce variations in care and increase effective service provision. ${ }^{1}$ The merit of applying this principle to mental health is well understood. 2,3 Over 20 years, four successive national mental health plans have each called for this kind of accountability. Despite the rhetoric, and as we now brace for a fifth plan, Australia still has no agreed set of priority indicators nor any process to enable useful benchmarking.

This is a critical management deficiency recognised by the National Mental Health Commission and the Mental Health Commission of New South Wales, which have both recently (and separately) published sets of preferred key indicators. ${ }^{4,5}$ Repeated Australian reports and reviews suggest mental health services are still best characterised as fragmented, ${ }^{6}$ bedevilled by major gaps in provision, ${ }^{7}$ inequitably distributed, ${ }^{8}$ increasingly costly (http://mhaustralia.org/submission/ mental-health-australia-submission-senate-inquiry-extentincome-inequality-australia) and outcome blind. ${ }^{9}$

Australia's current data collection systems focus on activity rather than outcomes and are typically aggregated to state and national levels. Local opportunities for benchmarking are limited to comparing inputs and processes, such as bed numbers and length of stay, and have not evolved to permit comparison of outcomes. Previous attempts to develop nationwide approaches to data definitions and reporting have proven a glacial (and expensive) affair. We propose a new, limited set of indicators for mental health that have the capacity to drive reform.

These should not only be useful nationally but also regionally. Evidence of the utility of such regional comparisons is strong and growing. ${ }^{4,10}$ There are significant regional differences in relation to issues such as suicide and rates of access to mental health care. Data need to be available at this level, rather than just statewide, to permit useful comparisons and propel reform.

An additional consideration is that the chosen indicators must reflect the broader concerns of the community and the validated experience of consumers, carers and service providers. Current data collections focus on governmental reporting requirements and do not reflect the social priorities that are evident in mental health care, such as in relation to social participation, employment and homelessness.

In proposing specific indicators, we build on our previous proposals on national service priorities. ${ }^{3}$ We propose 12 indicators across three domains (health, social and system reform), consistent with the core value of the National

\section{Summary}

- Greatly enhanced accountability can drive mental health reform. As extant approaches are ineffective, we propose a new approach.

- Australia spends around \$7.6 billion on mental health services annually, but is anybody getting better?

- Effective accountability for mental health can reduce variation in care and increase effective service provision.

- Despite 20 years of rhetoric, Australia's approach to accountability in mental health is overly focused on fulfilling governmental reporting requirements rather than using data to drive reform.

- The existing system is both fragmented and outcome blind. Australia has failed to develop useful local and regional approaches to benchmarking in mental health.

- New approaches must address this gap and better reflect the experience of care felt by consumers and carers, as well as by service providers. There are important social priorities in mental health that must be assessed.

- We provide a brief overview of the existing system and propose a new, modest but achievable set of indicators by which to monitor the progress of national mental health reform.

- These indicators should form part of a new, systemwide process of continuous quality improvement in mental health care and suicide prevention.

Mental Health Commission - the right to lead a contributing life.

The indicators emphasise proximal factors (eg, death rates in the 12 months after discharge from a health facility) that can drive reform, rather than distal outcomes that are likely to reflect more complex determinants acting over longer time frames (eg, life expectancy).

The 12 indicators are set out below, with a brief outline of current data and any limitations in relation to their current collection or use.

\section{Health domain indicators}

\section{Suicide rate: attempts and completions}

These data are already collected and reported, including in relation to the Indigenous community where the problem is acute. ${ }^{11}$ Data on suicide attempts are not available in Australia, unlike elsewhere. ${ }^{12}$ Data on completed and attempted suicides are needed at the regional level to support local, tailored prevention activities. In 2003, there were 2214 suicides and in 2013, there 
were 2522. ${ }^{13}$ By comparison, a national campaign has seen the road toll decrease from 1621 in 2003 to 1156 in $2014 .^{14}$

Death rates $<3$ and $<12$ months after discharge from any mental health facility, including cause of death

These data are not collected, with infrequent exceptions. ${ }^{15}$ Cause of death permits new, vital linkage of mental and physical illness, critical given the frequency of comorbidities.

Proportion of the population receiving mental health care services - both among the general population and, specifically, the population aged 12-25 years

These data are already collected and reported every decade. There is recent evidence indicating some lift in the rate of overall access to care, mainly due to the Better Access to Psychiatrists, Psychologists and General Practitioners through the Medicare Benefits Schedule initiative, $^{16}$ now costing around $\$ 15$ million per week. ${ }^{17}$ However, with $75 \%$ of all mental illnesses manifesting before the age of 25 years, ${ }^{18}$ it is vital also to monitor access by young people, ${ }^{19}$ including to new e-mental health, early intervention and online services. ${ }^{20}$ For young men, the access rate is as low as $13 \%$. This indicator would help to track whether services designed to meet the needs of young people were reaching their target audience.

\section{Prevalence of mental illness}

Prevalence data are already collected every decade. It would be useful to present these data by region in future iterations, to build understanding of comparative community resilience and vulnerability, and to better target resources where they are needed most.

\section{Social domain indicators}

\section{Participation rates by people with a mental illness of working age in employment}

Having a job is critical to the health, welfare and dignity of people with a mental illness. ${ }^{21}$ Addressing unemployment and minimising welfare spending has been a clear social priority for successive governments. Despite this confluence of interests, there is no current specific national data collection. The Organisation for Economic Cooperation and Development ranks Australia lowest in terms of the income of people with a severe mental disorder as a ratio of the average income of the population. ${ }^{22}$

\section{Participation rates by people with mental illness aged 16-30 years in education and training}

When young people are exhorted to "earn or learn", it is critical to monitor their education outcomes. This is being done elsewhere (eg, the United Kingdom Office for National Statistics) but not in Australia.

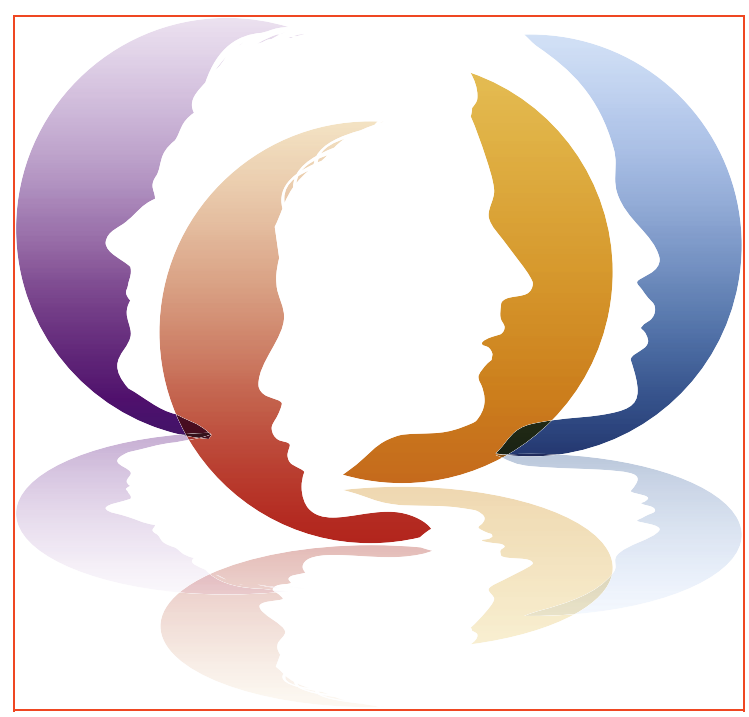

\section{People with a mental illness reporting they have stable housing}

Each night, 105000 Australians are homeless. ${ }^{23}$ It is estimated that more than a third of people who are homeless in inner city areas have severe mental illness. ${ }^{24}$ There is currently no specific data collection. Discharge into homelessness still occurs. These data would tell us about the impact of housing and supported accommodation services.

\section{Community surveys of attitudes towards mental illness}

Recovery is more likely when clinicians and service providers understand the social realities that people with a mental illness face in their daily lives. ${ }^{25}$ Community education campaigns help to demystify mental illness and counter stereotypes. ${ }^{26}$ Although some information exists, there is no regular national survey of community (and business) attitudes and stigma towards mental illness.

\section{System domain indicators}

\section{Consumer and carer experience of care}

Patient satisfaction is one of the core ingredients in making a service system accountable, transparent and responsive. 9,27 There are no nationwide validated data collected on the experience of care of mental health consumers and carers.

\section{Readmission rates to hospital or re-presentation to emergency departments within 28 days after discharge}

Some readmission data are already reported. In 2010-11, the proportion of admissions to state and territory acute psychiatric inpatient units that were followed by a readmission within 28 days was $15 \%$ nationally. ${ }^{28}$ This figure has been stable since 2005-06. This indicator 
would enable detailed comparison of the approach taken to arranging community support on discharge from one region to another.

\section{Life expectancy for people with severe and persistent mental illness}

This measure has been reported previously, with the life expectancy of this cohort much shorter than that of the general community. ${ }^{29}$ This indicator would highlight the extent to which the mental health care system is addressing the complex needs of the cohort, managing both physical and mental health issues, housing and other matters.

\section{Number of people accessing specialised programs to enhance economic and social recovery}

In the community-managed mental health sector, no service-level data are currently reported. This measure would at least monitor whether the community mental health sector is becoming a more significant player in Australia's mental health system.

\section{Conclusion}

There are clearly other areas of interest beyond the indicators listed here, including smoking rates, comorbidities and cost. There would also be considerable merit in tracking spending on mental health research so as to gauge our capacity to innovate.

There are currently hundreds of mental health indicators and multiple reports. We contend that very little of this information is used or usable at the local level to drive reform, and that much of this data collection should cease. All Australian governments should agree now to refocus their reporting priorities around these 12 indicators. Governance of their collection should reside in a body suitably independent from government which can identify gaps and inequity. This was an essential role played by the New Zealand Mental Health Commission ${ }^{30}$ but is yet to emerge in Australia.

It is critical that these indicators do not sit apart from a new, system-wide process of continuous quality improvement in mental health care and suicide prevention. No such process currently exists. This focused approach, around 12 agreed indicators, should drive quality improvement by making data available at the regional level for benchmarking by service providers, funders, decision makers and, importantly, consumers and carers. Every community wants to know the extent to which it has a mental health system on which it can rely. Local empowerment is the engine of mental health reform, and timely, useful accountability data are the fuel.

A further step would be to set some targets for these measures that reflect the scope and ambition of mental health reform in Australia. Across a myriad mental health plans and policies, this is yet to be articulated and is now long overdue.

Competing interests: lan Hickie is a member of the National Mental Health Commission.

Provenance: Not commissioned; externally peer reviewed.

() 2015 AMPCo Pty Ltd. Produced with Elsevier B.V. All rights reserved.

References are available online at www.mja.com.au. 
1 Institute of Medicine (US) Committee on Crossing the Quality Chasm: Adaptation to Mental Health and Addictive Disorders. Improving the quality of health care for mental and substance-use conditions: quality chasm series. Washington: National Academies Press, 2006.

2 Leeder S. Telling the story of mental health. Med J Aust 2015; 202: 161. https://www.mja.com.au/journal/2015/202/4/ telling-story-mental-health

3 Hickie I, McGorry P, Davenport T, et al. Getting mental health reform back on track: a leadership challenge for the new Australian Government. Med J Aust 2014; 200: 445-448. https://www.mja.com.au/journal/2014/200/8/getting-mentalhealth-reform-back-track-leadership-challenge-newaustralian

4 National Mental Health Commission Expert Reference Group to COAG Working Group on Mental Health Reform on National Targets and Indicators for Mental Health Reform. Final report. September 2013. http://www. mentalhealthcommission.gov.au/media/80181/250913\%20-\% 20ERG\%20final\%20report\%20to\%20WGMHR.pdf (accessed Mar 2015).

5 Mental Health Commission of New South Wales. Living well: a strategic plan for mental health in NSW 2014-2024. Sydney: MHCNSW, 2014. http://nswmentalhealthcommission.com.au/ our-work/strategic-plan (accessed Mar 2015).

6 Rosen A. Must try harder: Australia's half-hearted attempts at transition from hospital-centric to community-based mental health services. In Mendoza J, Bresnan A, Rosenberg S, et al, editors. Obsessive hope disorder: reflections on 30 years of mental health reform in Australia and visions for the future. Perspectives report. Caloundra, Qld: ConNetica, 2013.

7 Senate Select Committee on Mental Health. A national approach to mental health - from crisis to community. First report. Canberra: Parliament of Australia, 2006.

8 Meadows G, Enticott J, Inder B, et al. Better access to mental health care and the failure of the Medicare principle of universality. Med J Aust 2015; 202: 190-194. https://www.mja. com.au/journal/2015/202/4/better-access-mental-healthcare-and-failure-medicare-principle-universality

9 Crosbie D, Mental health policy - stumbling in the dark? Med J Aust 2009; 190(4 Suppl): S43-S45. https://www. mja.com.au/journal/2009/190/4/mental-health-policystumbling-dark

10 Salvador-Carulla L, Alvarez-Galvez J, Romero C, et al. Evaluation of an integrated system for classification, assessment and comparison of services for long-term care in Europe: the eDESDE-LTC study. BMC Health Serv Res 2013; 13: 1-12.

11 Australian Government. Closing the Gap: Prime Minister's Report 2015. Canberra: Commonwealth of Australia, 2015. http://www.dpmc.gov.au/sites/default/files/ publications/Closing_the_Gap_2015_Report.pdf (accessed Mar 2015).

12 Adolescent Suicide Attempt Data System. Oregon (US) Health Authority. http://public.health.oregon.gov/Prevention Wellness/SafeLiving/SuicidePrevention/Pages/ASADS2.aspx (accessed Mar 2015).

13 Australian Bureau of Statistics. Causes of death. Canberra: ABS, 2013. (ABS Cat. No. 3303.0). http://www.abs.gov.au/
ausstats/abs@.nsf/Lookup/by\%20Subject/3303.0 2013 Main\%20Features Key\%20Characteristics 10009 (accessed Apr 2015).

14 Australian Government Department of Infrastructure and Regional Development. Road trauma Australia: 2014 statistical summary. Canberra: DIRD, 2014. http://bitre.gov.au/ publications/ongoing/files/Road_trauma_Australia_2014_ statistical_summary_N_ISSN.pdf (accessed Sep 2015).

15 Davidson R. Chief Psychiatrist's review of clinical practice. Admissions and discharges of mental health presentations: Fremantle Hospital. Perth: Government of Western Australia, Department of Health, 2012. http://www.chiefpsychiatrist. health.wa.gov.au/docs/Admissions_and_Discharges_of_Mental_ Health_Presentations_Report_June_2012.pdf (accessed Mar 2015).

16 Whiteford $\mathrm{H}$, Buckingham W, Harris $\mathrm{M}$, et al. Estimating treatment rates for mental disorders in Australia. Aust Health Rev 2014; 38: 80-85.

17 Australian Government Department of Human Services. Medicare item reports. http://medicarestatistics. humanservices.gov.au/statistics/mbs_item.jsp (accessed Sep 2015).

18 McGorry P, Purcell R, Hickie IB, Jorm A. Investing in youth mental health is a best buy. Med J Aust 2007; 187: 5. https:// www.mja.com.au/journal/2007/187/7/investing-youth-mentalhealth-best-buy

19 McGorry P, Tanti C, Stokes R, et al. headspace: Australia's National Youth Mental Health Foundation - where young minds come first. Med J Aust 2007; 187: 68. https:// www.mja.com.au/journal/2007/187/7/headspace-australia-snational-youth-mental-health-foundation-where-youngminds

20 Burns J, Davenport T, Christensen H, et al. Game on: exploring the impact of technologies on young men's mental health and wellbeing. Young and Well Cooperative Research Centre, July 2013. http://www.youngandwellcrc.org.au/wp-content/ uploads/2014/03/Young_and_Well_CRC_Game_On_Report.pdf (accessed Mar 2015).

21 Paul K, Moser K. Unemployment impairs mental health: metaanalyses. J Vocat Behav 2009; 74: 264-282.

22 Organisation for Economic Co-operation and Development. Sick on the job? Myths and realities about mental health and work. Paris: OECD, 2012.

23 Australian Government. The road home: a national approach to reducing homelessness. Canberra: Commonwealth of Australia, 2007.

24 Herrman $\mathrm{H}$, Evert $\mathrm{H}$, Harvey $\mathrm{C}$, et al. Disability and service use among homeless people living with psychotic disorders. Aust $N$ Z J Psychiatry 2004; 38: 965-974.

25 Rabkin J. Public attitudes toward mental illness, a review of the literature. Schizophr Bull 1974; 1: 9-33.

26 Hocking B. Reducing mental illness stigma and discrimination - everybody's business. Med J Aust 2003; 178: 47-48. https:// www.mja.com.au/journal/2003/178/9/reducing-mentalillness-stigma-and-discrimination-everybodys-business

27 Australian Health Ministers. National mental health plan 2003-2008. Canberra: Australian Government, 2003.

28 Department of Health and Ageing. National mental health report 2013: tracking progress of mental health reform in 
Australia 1993-2011. Canberra: Commonwealth of Australia, 2013. https://www.health.gov.au/internet/main/publishing. nsf/content/B090F03865A7FAB9CA257C1B0079E198/\$File/ repl3.pdf (accessed Sep 2015).

29 Lawrence D, Hancock K, Kisely S. The gap in life expectancy from preventable physical illness in psychiatric patients in
Western Australia: retrospective analysis of population based registers. BMJ 2013; 346: f2539.

30 New Zealand Mental Health Commission. National indicators 2012. http://www.hdc.org.nz/media/215430/ national\%20indicators\%202012.pdf (accessed Jun 2015). 